\title{
Avaliação dos efeitos da Resolução RDC 17 sobre fitoterápicos de registros antigos
}

\author{
Virgílio, L.J.'; Marques, L.C. ${ }^{{ }^{*}}$ \\ ${ }^{1}$ Farmacêutico, estudante do curso de pós-graduação em \\ Manipulação Magistral do Instituto Racine; \\ 2 Professor de Farmacognosia (licenciado) da Universidade \\ Estadual de Maringá; ministrante do curso de pós-graduação \\ em Manipulação Magistral do Instituto Racine
}

\section{Resumo}

Avaliou-se qualitativamente o mercado brasileiro de fitoterápicos a partir de medicamentos registrados anteriormente à 1995 como expressão do conjunto de produtos fitoterápicos antigos em mercado. Foram adquiridos nove produtos de farmácias comerciais de São Paulo registrados há décadas, contendo exclusivamente fitoterápicos ou misturados a fármacos sintéticos. Foram avaliados aspectos de conteúdo, rotulagem e bula; em complemento, buscou-se avaliar o andamento dos estudos de toxicidade e eficácia. Todos os nove medicamentos apresentaram problemas na rotulagem e bula, destacandose a falta das seguintes informações: mecanismos de ação do produto $(100 \%)$, parte usada $(78 \%)$, super-dosagens (67\%), cuidados com crianças e idosos $(56 \%)$, cuidados de conservação $(22 \%)$ e riscos dos produtos $(11 \%)$. Em relação aos estudos de segurança e eficácia, apenas dois laboratórios (2/9) se posicionaram de maneira esclarecedora e informaram o andamento dos mesmos. Verifica-se, portanto, que os medicamentos de registro antigo, por diversos motivos, encontram-se fora dos padrões legais exigidos.

\begin{abstract}
The Brazilian market of phytomedicine from registered medicines previously to the 1995 was evaluated qualitatively as expression of the set of old products in market. Nine old registered commercialy pharmacy products of São Paulo contend exclusively extracts of plants or mixed with synthetic drugs. Aspects of content, labeling and informations for use had been evaluated; in complement, one searched to evaluate the course of the toxicidade studies and effectiveness. All the nine medicines had presented problems in the labeling and informations for use, being distinguished lacks it of the following information: mechanisms of action (100\%), used part (78\%), superdosages $(67 \%)$, cares with old people and children $(56 \%)$, cares of conservation (22\%) and risks of the products (11\%). In relation to the studies of security guard and effectiveness, only two laboratories (2/9) informed the course of the same ones. It is verified therefore that the medicines of old register, for diverse reasons, meet outside of the demanded legal standards.
\end{abstract}


A Portaria SVS $n^{\circ}$ 6, de 31 de janeiro de 1995 (BRASIL, 1995), tornou-se um marco regulatório dos fitoterápicos brasileiros, pois foi a primeira norma moderna a regulamentar essa classe de medicamentos (MARQUES, 2003); suas exigências foram estabelecidas para serem cumpridas em duas etapas de 5 anos, encerrando-se em 30 de janeiro de 2005. Sua atualização ocorreu por meio da Resolução RDC $n^{\circ} 17$ (BRASIL, 2000) e mais recentemente com a edição da RDC n ${ }^{\circ} 48$ (BRASIL, 2004), com amplas modificações técnicas e eliminação daqueles prazos anteriormente definidos.

No entanto, por questões de direito adquirido, produtos que encontravam-se registrados antes de 31.01.95, e para os quais pouca ou nenhuma informação técnica existia à época, buscaram enquadrar-se nas etapas definidas com programação da execução dos estudos de segurança e eficácia. Desse modo, embora as normas posteriores tenham alterado completamente esse esquema, para esses produtos de 'registro antigo', mantiveram-se os prazos anteriores, mesmo que informalmente, visando evitar problemas e conflitos judiciais.

As normas atuais, embora aprimoradas em muitos aspectos, não vem sendo aplicadas em sua totalidade visto que ainda são comercializados medicamentos sem registro ou apenas com protocolo, com informações incompletas e sem embasamento científico (CALIXTO, 2003).

Este trabalho buscou avaliar os medicamentos fitoterápicos de registro antigo presentes no mercado farmacêutico brasileiro buscando conhecer qualitativamente o grau das aplicações das normas vigentes sobre eles. Para isso, selecionou-se medicamentos registrados anteriormente a janeiro de 1995 avaliando-os quanto aos aspectos de rotulagem e os relacionados ao cumprimento dos estudos de segurança e eficácia.

Foram adquiridos nove medicamentos disponíveis no comércio local, sendo cinco com ingredientes exclusivamente vegetais e quatro com ativos sintéticos associados a extratos vegetais (tabela 1 ).

Tabela 1. Produtos avaliados, sua composição e nomenclatura botânica.

\begin{tabular}{|c|c|c|}
\hline $\mathbf{N}^{\mathbf{o}}$ & Composição & Nomes científicos das espécies \\
\hline 1 & Carqueja, quina e pau pereira & $\begin{array}{c}\text { Baccharis genistelloides, } \\
\text { Cinchona succirrubra, } \\
\text { Geiospermum leave }\end{array}$ \\
\hline 2 & Alcachofra e boldo do Chile & Cynara scolymus, Peumus boldus \\
\hline 3 & $\begin{array}{l}\text { Beladona, bálsamo do Perú, } \\
\text { cânfora, salicilato de metila e } \\
\text { óxido de zinco }\end{array}$ & ausentes \\
\hline 4 & Camomila vulgar e associações & Matricaria chamomila \\
\hline 5 & $\begin{array}{l}\text { Badiana, baunilha, iodeto de } \\
\text { potássio e associações }\end{array}$ & Ilicium verum, Vanila planifolia \\
\hline 6 & Maracujá, mulungú e erva-cidreira & $\begin{array}{c}\text { Passiflora alata, Erythrina mulungu, } \\
\text { Melissa officinalis }\end{array}$ \\
\hline 7 & Jaborandi & Pilocarpus pinnatifolium \\
\hline 8 & Catuaba e canela do Ceilão & $\begin{array}{c}\text { Trichilia catigua, } \\
\text { Cinnamommum zeylanicum }\end{array}$ \\
\hline 9 & Limão bravo e associações & Siparuna apiosyce \\
\hline
\end{tabular}

Esses produtos foram avaliados em relação à presença de dados gerais de identificação, envolvendo as informações: endereço, número de registro, farmacêutico responsável, CNPJ, lote, validade, data fabricação, forma farmacêutica, via de administração, peso/volume/número de unidades, frases de alerta gerais e frases específicas aos fitoterápicos. Esses itens, em sua quase totalidade, estavam presentes nos medicamentos; as frases específicas exigidas para fitoterápicos ('Medicamento Fitoterápico” ou “
Medicamento Fitoterápico Tradicional") foi encontrada em apenas 2 de 5 produtos onde deveriam existir, constituindose numa irregularidade frente à legislação em vigor à época.

Em outros aspectos, os produtos foram também verificados em relação a outras informações mais técnicas, tais como parte da planta utilizada, mecanismos de ação, indicações e contra-indicações e informações afins, todas igualmente exigidas em normas legais (tabela 2). 
Tabela 2. Informações de rotulagem presentes nos produtos avaliados.

\begin{tabular}{c|c|c}
\hline Informação & $\mathbf{N}^{\mathbf{0}}$ & $\mathbf{\%}$ \\
\hline Indicações terapêuticas & 9 & 100 \\
\hline riscos e efeitos colaterais & 8 & 89 \\
\hline posologia & 8 & 89 \\
\hline conservação & 7 & 78 \\
\hline uso em idosos e crianças & 4 & 44 \\
\hline superdosagem & 2 & 22 \\
\hline mecanismo de ação & 0 & 0 \\
\hline parte da planta & 0 & 0 \\
\hline
\end{tabular}

Um dos itens exigidos pela Resolução RDC 17 é que bulas e/ou cartuchos devam conter obrigatoriamente as diretrizes: "MEDICAMENTO EM ESTUDO PARA AVALIAÇÃO CIENTÍFICA DA TOXICIDADE E DAS INDICAÇÕES TERAPEUTICAS" e "MEDICAMENTO EM ESTUDO PARA AVALIAÇÃO CIENTÍFICA DAS INDICAÇÕES TERAPÊUTICAS", caso o produto não tenha disponibilidade de tais informações. Evidentemente, tais frases deveriam corresponder, em tese, aos respectivos estudos formalmente executados em instituições próprias das empresas ou em universidades públicas ou privadas, nas quais tais pesquisas costumam ocorrer.

As informações, solicitadas via telefone e correio eletrônico, expostas na tabela 3 , correspondem às tentativas de obtenção de informações concretas em relação a tais estudos ou ao menos de seu andamento.

Tabela 3. Situação dos produtos em relação aos estudos de segurança e eficácia.

\begin{tabular}{c|c|c}
\hline $\mathbf{N}^{\mathbf{0}}$ & $\begin{array}{c}\text { Presença da } \\
\text { frase "produto } \\
\text { em estudo..." }\end{array}$ & $\begin{array}{c}\text { Resposta sobre andamento dos } \\
\text { estudos }\end{array}$ \\
\hline 1 & Sim & Resposta insatisfatória ou incompleta \\
\hline 2 & Sim & Resposta insatisfatória ou incompleta \\
\hline 3 & NÃO & Resposta insatisfatória ou incompleta \\
\hline 4 & Sim & Resposta totalmente esclarecedora \\
\hline 5 & NÃO & Resposta insatisfatória ou incompleta \\
\hline 6 & NÃO & Resposta insatisfatória ou incompleta \\
\hline 7 & Sim & Resposta insatisfatória ou incompleta \\
\hline 8 & NÃO & Não foi possível comunicação \\
& & com a empresa \\
\hline 9 & NÃO & Resposta totalmente esclarecedora \\
\hline
\end{tabular}

Em relação aos esses dados, verifica-se que apenas em 2/9 casos foi possível obter respostas adequadas em relação ao andamento dos estudos de segurança e eficácia. Os outros laboratórios (6/9) se explicaram de diferentes modos, evidenciando contradições em relação ao desenvolvimento efetivo de tais estudos; um laboratório em particular admitiu estar aguardando definições legais no sentido da flexibilização de tais exigências pelo órgão regulador do Ministério da Saúde. Uma das empresas produtoras de produto contendo fármaco sintético comunicou que o mesmo não está mais registrado como fitoterápico, os restantes três laboratórios com produtos nessa situação não foram afirmativos nessa declaração.

Com base nesses produtos foi possível observar a existência de falhas importantes nos textos informativos das bulas, na comprovação da eficácia terapêutica e na segurança do medicamento. Embora alguns apresentassem em menor grau tais problemas, foi presenciado em todos os produtos.

Tal situação reflete o despreparo de algumas indústrias farmacêuticas na fabricação dos medicamentos e as dificuldades dos órgãos responsáveis para a fiscalização dos mesmos, enaltecendo a importância do acompanhamento desse processo de ajuste dos produtos antigos de modo que a lei venha de fato a ser aplicada e transforme os fitoterápicos clássicos brasileiros em produtos modernos e estudados, pois afinal estes são os objetivos principais das normas editadas.

\section{Materiais e Métodos}

Realizou-se um estudo qualitativo no qual foram selecionados, no período de novembro a dezembro de 2004 na cidade de São Paulo, alguns medicamentos, fitoterápicos de registros antigos; em complemento, foram incluídos também produtos sintéticos que apresentavam ingredientes vegetais e portanto que poderiam ou não ser classificados como fitoterápicos. A partir desses medicamentos foram avaliadas as rotulagens e buscou-se conhecer a existência ou programação de estudos de toxicologia e de eficácia.

Para a avaliação da rotulagem foram seguidas as recomendações das Resoluções RDC n ${ }^{\circ} 17$ e no 140 (BRASIL, 2000; 2003). Já para a avaliação dos estudos toxicológicos e de eficácia, foi verificada a presença de frases que devem aparecer obrigatoriamente nas bulas e/ou cartuchos alertando se o produto está em fase de estudos. Para saber mais detalhes sobre esse processo de revalidação do registro, as empresas foram contatadas via telefone e email, solicitando-se os esclarecimentos respectivos sobre os estudos.

\section{Referências}

${ }^{1}$ BRASIL. Ministério da Saúde. Agência Nacional de Vigilância Sanitária. Resolução RDC no 17, 24.02.2000. Dispõe sobre o registro de medicamentos fitoterápicos. Diário Oficial da União, 25.02.2000.

${ }^{2}$ BRASIL. Ministério da Saúde. Agência Nacional de Vigilância Sanitária. Resolução RDC no 140, 29.05.2003. Adota definições, instruções ou avisos que favorecem o uso correto, prudente e seguro do medicamento, para prevenir 
um agravo saúde, mas que, não necessariamente, o contraindique. Diário Oficial da União, 02.06.2003.

${ }^{3}$ BRASIL. Ministério da Saúde. Agência Nacional de Vigilância Sanitária. Resolução RDC no 48 de 16.03.2004. Dispõe sobre o registro de medicamentos fitoterápicos. Diário Oficial da União, 18.03.2004.

${ }^{4}$ BRASIL. Ministério da Saúde. Secretaria de Vigilância Sanitária. Portaria $\mathrm{n}^{\mathrm{o}} 6$ de 31.01.1995. Regulamenta o registro de fitoterápicos. Diário Oficial da União, 06.02.1995. ${ }^{5}$ Calixto, João Batista. Medicamento fitoterápico no Brasil: produção indiscriminada sem o cumprimento da lei. Disponível em<http://www.conteudoexpresso.com.br/ Mostra Conteúdo.asp>. Acesso em 20 nov. 2003, 01:10.

${ }^{6}$ Marques L.C. Normatização da produção e comercialização de fitoterápicos no Brasil. In: Simões C.M.O.; Schenkel E.P.; Gosmann G.; Mello J.C.P.; Mentz L.A.; Petrovick P.R. Farmacognosia: da planta ao medicamento. Porto Alegre/ Florianópolis: Editoras da UFRGS/UFSC, 2003.

\section{*Autor para correspondência}

Luis Carlos Marques

Av Pedro Taques, 1041 - Sala 06

Jardim Alvorada - 87030-000

Maringá - PR

e-mail:lmarques@teracom.com.br 